\title{
Thermal environment mitigation effects in suburban area
}

\author{
Yoshihito Kurazumi ${ }^{1, *}$, Emi Kondo ${ }^{2}$, Kenta Fukagawa ${ }^{3}$, Yoshiaki Yamato ${ }^{4}$, Kunihito Tobita ${ }^{5}$, and Tadahiro Tsuchikawa ${ }^{6}$ \\ ${ }^{1}$ School of Life Studies, Sugiyama Jogakuen University, Nagoya, Japan \\ ${ }^{2}$ Department of Architecture, Ariake National College of Technology, Omuta, Japan \\ ${ }^{3}$ Department of Architecture, Kyushu Sangyo University, Fukuoka, Japan \\ ${ }^{4}$ Department of Architecture and Structural Engineering, Kure National College of Technology, Kure, Japan \\ ${ }^{5}$ School of Humanities and Social Sciences, Osaka Prefecture University, Sakai, Japan \\ ${ }^{6}$ School of Human Science \& Environment, University of Hyogo, Himeji, Japan
}

\begin{abstract}
The purpose of this paper is to clarify the relationship between the physiological and psychological responses of the human body and the outdoor environment evaluation index ETFe (enhanced conductioncorrected modified effective temperature). The experiments were carried out in summer. For the measurements, observation points were selected with consideration for the condition of the ground surface such as bare ground where the surface is gravel or soil; paved ground such as concrete, asphalt or blocks; green areas covered in plants and water surfaces and with consideration for the condition of the sky factor due to buildings or trees. 19 observation points were chosen. Subjects were 38 healthy young. ETFe that was considered to report neither hot nor cold, thermally neutral sensation, was $30.6^{\circ} \mathrm{C}$. ETFe that was considered to report neither comfortable nor uncomfortable comfort was $35.5^{\circ} \mathrm{C}$. It was considered that the threshold for the human body with regards to thermal environment stimuli in an outdoor space is higher than the thermal environment stimuli in a summer indoor space.
\end{abstract}

\section{Introduction}

Ishii et al. [1], Fukagawa et al. [2, 3], etc. measure the influence of park lakes, agricultural ponds, etc., on the summer outdoor thermal environment. The environment is influenced by the depth of water, the temperature of the surface of the water and the direction of the wind, but the trend is observed whereby the air temperature tends to be lower directly above the water surface and in the vicinity of the pond compared to the surrounding area. However, they consider air temperature reduction effect to be within a limited range. If the temperature of the water surface is higher than the air temperature, the air temperature on the downwind side of a pond across which wind blows tends to increase.

Kurazumi et al. [4-6] demonstrates the influence of an outdoor thermal environment on the human body with the outdoor thermal environment evaluation index ETFe [7] for the influence of a tropical climate with strong shortwave length solar radiation on the thermal sensation of the human body as the evaluation axis. It clarifies that in tropical areas where the effects of nighttime cooling cannot be expected, the effect of long-wave length thermal radiation is strong in the shade of objects made of materials with high heat capacity, and the effect of improving the thermal sensation of the human body through shade is low. These studies quantitatively show that when the outdoor thermal environment is harsh, it is essential to reduce the influence of long-wave length thermal radiation.
Kurazumi et al. [8-10] quantitatively evaluates the influence on the human body in the outdoor thermal environment using enhanced conduction-corrected modified effective temperature (ETFe) [7] as an evaluation axis. In this series of studies, the sense of expectation with regards to comfort in outdoor spaces is low and the subjects are not judged to be comfortable thermal environments, so it is considered that even thermal environmental conditions with a high ETFe and thermal environmental conditions with high mean skin temperature can be tolerated as well as thermal environment conditions with a low ETFe and thermal environmental conditions with low mean skin temperature. The outdoor thermal environment being in a harsh condition is shown quantitatively by the outdoor thermal environment evaluation index EFTe.

From the above, in a summer outdoor space, natural ground surfaces such as green spaces and water surfaces are useful in reducing the air temperature. However, concerning the effects of water surfaces, water depth, water flow and water temperature influence the temperature reduction effect.

Therefore, this study focused on the suburban region where paddy fields still remain, and aimed to clarify the relationship between outdoor thermal environment evaluation index ETFe [7], which Kurazumi et al. [8] verifies validity as an outdoor thermal environment evaluation index, and the response of the human body with respect to thermal sensory perception. We decided to collect phenomena and information to quantitatively

\footnotetext{
* Corresponding author: kurazumi@sugiyama-u.ac.jp
} 
examine the outdoor thermal environment and effects on the human body.

\section{Experimental plan}

The thermal environment evaluation index for an outdoor space ETFe (enhanced conduction-corrected modified effective temperature) was developed by Kurazumi et al. [7]. Also, verification tests that clarify the relationship between ETFe and the physiological and psychological effect on the human body have been carried out, and its effectiveness as an outdoor environmental evaluation index has been clarified [8]. This sensational and physiological climatic environment index ETFe is considered to enable temperature-conversion of each effect of wind speed, long-wave length thermal radiation in the outdoor space, short-wave length radiation, surface temperature of the material in contact with the human body and humidity into individual meteorological elements.

Experiments were conducted in late July 2016 and from late August 2015 to the beginning of September. The observation points were drawn at random and the route to the points was undecided.

The movement speed of the subjects was made about $0.7 \mathrm{~m} / \mathrm{s}$. After arriving at each measurement point, the subjects waited in a standing posture, during which time the experiment staff set up the measurement instruments for the thermal environment and preparations for measurement were concluded. Thereafter, the subjects were exposed to the thermal environment in a standing posture for ten minutes, as detailed above. The subjects were positioned around the thermal environment measurement instruments with the thermal environment measurement instruments in the center. As the subject of the research was the environment surrounding the observation stations, the point of gaze of the subjects was free and unfixed. After exposure, the subjects reported the average thermal senses for the whole body that they experienced for the time exposed at the observation point.

Table 1 shows a summary of the observation points. Observation points were selected with consideration for the natural ground surface such as bare ground where the surface is gravel or soil; paved ground such as concrete, asphalt or blocks; green areas covered in plants; and water surfaces, as well as the condition of sky factor due to buildings or trees etc. and the proportion of the solid angle of components of greenery and water etc. comprising the solid angle of the total celestial sphere (hereafter, green factor). Nineteen observation points were chosen.

The subjects were 38 healthy young males and females. In accordance with the Helsinki Declaration [11], the details of the experiment were fully explained to the subjects in advance and their consent to participate in the experiment was obtained.

Air temperature and humidity, wind speed, short-wave length solar radiation, long-wave length thermal radiation, ground surface temperature of the central part of the experimental equipment, and sky factor were measured as thermal environment conditions.
Table 1. Summary of observation points.

\begin{tabular}{rlccc}
\hline Point & \multicolumn{1}{c}{ Survey site } & Ground surface & $\begin{array}{c}\text { Sky } \\
\text { factor }\end{array}$ & $\begin{array}{c}\text { Green } \\
\text { factor }\end{array}$ \\
\hline 1 & Building canyon & Asphalt \& Weed & 0.295 & 0.116 \\
2 & Playground bare area & Grass & 0.920 & 0.046 \\
3 & Playground green area & Bare ground & 0.951 & 0.481 \\
4 & Roard side & Asphalt & 0.873 & 0.046 \\
5 & Wisteria trellis & Bare ground & 0.104 & 0.135 \\
6 & Paddy side & Asphalt \& Paddy field & 0.938 & 0.132 \\
7 & Farmland side & Weed & 0.506 & 0.338 \\
8 & On the bridge & Concrete \& River & 0.913 & 0.035 \\
9 & River side & Gravel \& Weed \& River & 0.352 & 0.411 \\
10 & Square & Grass \& Weed & 0.870 & 0.532 \\
11 & Residencial area alley & Asphalt & 0.690 & 0.019 \\
12 & Revetment canyon & Stone revetment & 0.620 & 0.157 \\
13 & Roade side & Asphalt & 0.718 & 0.000 \\
14 & Bus stop & Asphalt \& Weed & 0.359 & 0.306 \\
15 & Building canyon & Asphalt \& Weed & 0.287 & 0.051 \\
16 & Playground green area & Grass & 0.852 & 0.534 \\
17 & Roade side & Asphalt & 0.864 & 0.091 \\
18 & Paddy side & Asphalt \& Paddy field & 0.881 & 0.100 \\
19 & River side & Gravel \& Weed \& River & 0.109 & 0.556 \\
\hline
\end{tabular}

Green factor is green covering factor. Green covering factor is defined as the ratio of green, water surface solid angles to celestial globe solid angle.

Skin temperature was measured as a physiological condition for the human body. The temperature of skin was measured at the eight positions of the head, trunk, arm, hand, thigh, lower leg, foot, and sole of the foot. The subjects freely selected their clothing to be suitable to the weather on the measurement day.

As a psychological condition for the human body, the psychological response was measured after staying at the observation point for ten minutes by means of a linear scale.

\section{Results}

The short-wave length solar radiation downwards differed greatly in the sun and in the shade. Although it depends on the solar altitude and solar azimuth, and the influence of shielding on the south side, downward short-wave length solar radiation becomes stronger the higher the sky ratio of the observation site. Long-wave length thermal radiation is large at every observation site, and the influence of downward and upward thermal radiation is considered to be strong even at observation sites where direct solar radiation is shielded. There is no remarkable difference between the average values of downward short-wave length solar radiation and downward longwave length thermal radiation, and the intensity of longwave length thermal radiation from the ground surface is shown. Therefore, it is considered that large environmental mitigation effect cannot be expected by simply seeking shade.

Instances where the temperature of the ground surface exceeds $60{ }^{\circ} \mathrm{C}$ are also indicated at observation sites covered by asphalt pavement. Although the air temperature also has an effect, the influence of heating by downward short-wave length solar radiation and solar radiation absorptivity of the ground surface is observed.

The average value of the relative humidity is $72.8 \%$, the standard deviation is $7.3 \%$. Average wind speed was $1.1 \mathrm{~m} / \mathrm{s}$ and under $3 \mathrm{~m} / \mathrm{s}$ throughout all observations. 


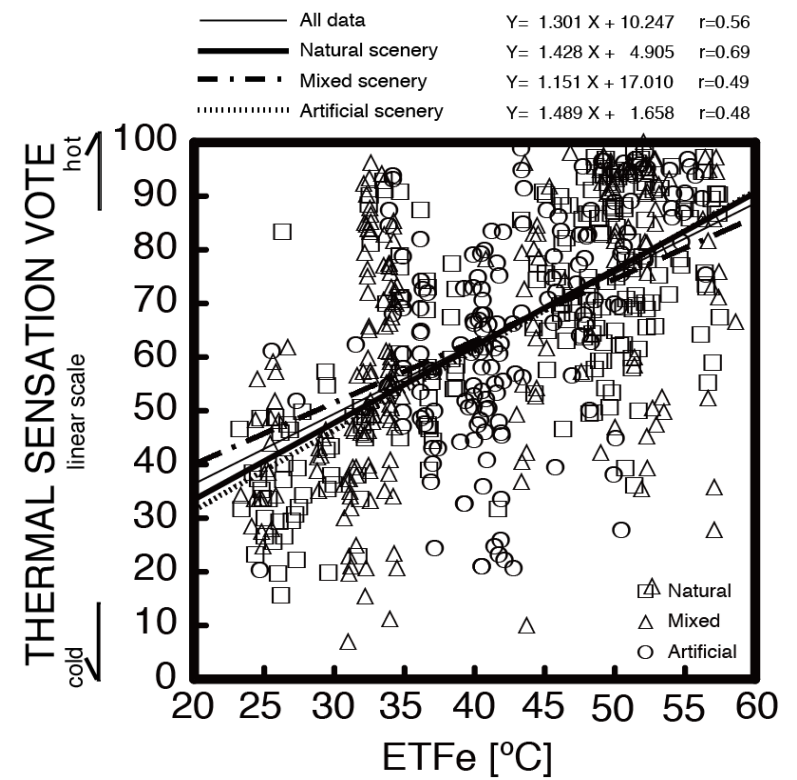

Fig. 1. Relationship between ETFe and thermal sensation.

\section{Discussions}

Fig. 1 shows the relationship between ETFe and thermal sensation. Environmental stimuli in outdoor spaces are in a heterogeneous and unsteady state.

These evaluation factors may contribute as a local effect on the human body, even if the heat balance in the whole human body is the same. Horikoshi et al. [12] clarifies that the psychological reactions of the human body in a heterogeneous/asymmetric thermal radiation environment have directionality which changes under the effect of local thermal radiation. Kurazumi et al. [13, 14] clarify that a parameter exists for the heterogeneous/asymmetric thermal environmental factors in the thermal environment evaluation factors that evaluate the effect on the human body in a heterogeneous/asymmetric thermal radiation environment. They show that there is a large spread in the response of the human body due to the effect of this parameter.

Kurazumi et al. [15] considers green factor to influence the thermal sensation of the human body. Taking less than $10 \%$ as artificial scenery, over $10 \%$ and less than $30 \%$ as mixed scenery, and $30 \%$ or more as natural scenery in order to grasp the relationship between the environment and the human body reaction makes it easy to explain the interaction. Accordingly, the relationship between ETFe and thermal sensation was examined by the green factor classification of Kurazumi et al. [16].

The mixed scenery observation point with high ETFe is 18 Paddy side. The condition of 18 is strong short-wave length solar radiation and long-wave length thermal radiation from the ground surface. Nishida et al. [17] considers the environmental mitigation effect of the surface of paddy field to be related to water depth and water flow. The measurement period is at the ripening stage of the head of the rice, so the short-wave length solar radiation shielding rate on the water surface is high, but due to the fact that there is no flow of water and the heat

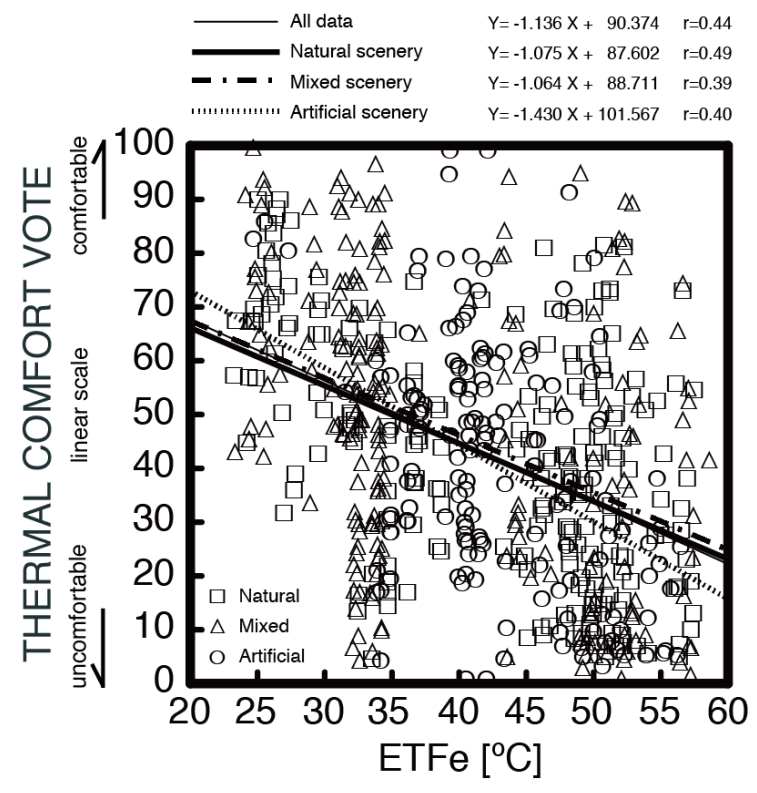

Fig. 2. Relationship between ETFe and thermal comfort.

capacity is high, in the time period when there is a large cumulative amount of short-wave length solar radiation, long-wave length thermal radiation may increase.

As pointed out by Kurazumi et al. [15], it is conjectured that there is also a visual influence due to the natural surface coverage by vegetation, etc. However, natural scenery shows a thermal sensation slightly hotter than mixed scenery, giving a result whereby the effect of natural surface coverage by vegetation, etc. is not apparent. Fukagawa et al. [17] and Kurazumi et al. [1820] consider a landscape of thick vegetation with a high green factor to have a strong feeling of confinement, which makes it somewhat hot and somewhat uncomfortable thermal environment due to the sense of stagnation. In this study too, it can be conjectured that thermal sensation increased due to the influence of the green factor enhancing this sense of confinement.

Therefore, it can be said that ground surface features with a high heat capacity and situations that evoke a feeling of confinement tend to increase the thermal sensation by promoting the sensation of hot.

Focusing on the regression line for all experimental results, the ETFe that gives a neither hot nor cold, thermally neutral thermal sensation of 50 is $30.6{ }^{\circ} \mathrm{C}$. In this study on suburban region, the ETFe that gives a neutral thermal sensation of 50 is low in comparison to the subject experiments in the urban environment in Kurazumi et al. [8-10]. Compared with the urban environment, it is conceivable that the difference in the perceptual environment, whereby it is subconsciously assumed to be a comfortable thermal environment, had an effect in the suburban regional environment.

Fig. 2 shows the relationship between ETFe and thermal comfort. As stated in "Relationship between ETFe and thermal sensation", environmental stimuli in outdoor spaces are in a heterogeneous and unsteady state. The human body may experience discomfort due to changing environmental factors, and so this experience can be thought to induce the condition of relative comfort. Accordingly, changes with an effect that mitigates 
thermal function are considered to be variables for discomfort with regards to other environmental factors also [8-10].

Focusing on the regression line, the Thermal comfort tends to be lower as ETFe becomes higher. The tenancy was shown for artificial scenery to have the strongest level of discomfort. As identified by Kurazumi et al. [15], it is conjectured that there is also a visual influence due to the natural surface coverage by vegetation, etc.

Focusing on the regression line for all experimental results, the ETFe that gives a neither comfortable nor uncomfortable thermal comfort of 50 is $35.5^{\circ} \mathrm{C}$. In this study on the suburban region, the ETFe that gives a neither comfortable nor uncomfortable thermal comfort of 50 is low in comparison to the subject experiments in the urban environment in Kurazumi et al. [8-10]. Compared with the urban environment, it is conceivable that the difference in the perceptual environment, whereby it is subconsciously assumed to be a comfortable thermal environment, had an effect in the suburban regional environment.

\section{Conclusions}

Focusing on the suburban region where paddy fields remain, subject experiments were conducted to clarify the effect of thermal environmental factors on the human body in an outdoor space.

Paddy fields, in which the water that has received short-wave length solar radiation does not flow, have a high heat capacity, which works to increase the long-wave length thermal radiation in the time period when the accumulated amount of short-wave length solar radiation increases. A ground surface feature with a high heat capacity may promote sensation of hot and deteriorate the thermal sensation.

The ETFe that gives a neither hot nor cold, thermally neutral thermal sensation was $30.6{ }^{\circ} \mathrm{C}$. The ETFe that gives a neither comfortable nor uncomfortable thermal comfort was $35.5^{\circ} \mathrm{C}$.

\section{References}

1. A. Ishii, T. Katayama, M. Nishida, T. Hayashi, Y. Shiozuki, J. Tutsumi, H. Kitayama, K. Takayama, H. Murooka, M. Ooguro, Summaries of Technical Papers of Annual Meeting Archtectural Institute of Japan, D Environmental Engineering, 1087-1088 (1989)

2. K. Fukagawa, T. Shimazawa, S. Muranaka, Y. Koshikawa, M. Ando, Journal of Environmental Engineering, 605, 95-102 (2006)

3. K. Fukagawa, S. Murakawa, D. Nishida, T. Shimazawa, Journal of Environmental Engineering, 626, 503-510 (2008)

4. Y. Kurazumi, J. Ishii, K. Fukagawa, A. Aruninta, International Joint-Conference of SENVARiNTA-AVAN 2015, Johor, Malaysia, 24-26 November 24-26 2015, 105-114 (2015)
5. Y. Kurazumi, J. Ishii, K. Fukagawa, E. Kondo, A. Aruninta, American Journal of Climate Change, 5(1), 52-68 (2016)

6. Y. Kurazumi, J. Ishii, K. Fukagawa, E. Kondo, A. Nyilas, A., Aruninta, Health, 9(6), 896-920 (2017)

7. Y. Kurazumi, K. Fukagawa, Y. Yamato, K. Tobita, E. Kondo, T. Tsuchikawa, T. Horikoshi, N. Matsubara, Building and Environment, 46(1), 12-21 (2011)

8. Y. Kurazumi, T. Tsuchikawa, N. Matsubara, E. Kondo, T. Horikoshi, Energy and Buildings, 43(10), 2925-2937 (2011)

9. Y. Kurazumi, T. Tsuchikawa, E. Kondo, J. Ishii, K. Fukagawa, Y. Yamato, K. Tobita, Y. Ando, N. Matsubara, T. Horikoshi, Journal of Human and Living Environment, 19(2), 115-127 (2012)

10. Y. Kurazumi, J. Ishii, E. Kondo, K. Fukagawa, Z.D. Bolashikov, T. Sakoi, T. Tsuchikawa, N. Matsubara, T. Horikoshi, International Journal of Biometeorology, 58(5), 963-974 (2014)

11. World Medical Association, http://www.wma.net/en/30publications/10polici es/b3/index.html (accessed 30 October 2018).

12. T. Horikoshi, Y. Kurazumi, K. Hirayama, T. Tsuchikawa, Y. Kobayashi, CLIMA 2000 III, Sarajevo, Yugoslavia, August 27-September 1 1989, 188-193 (1989)

13. Y. Kurazumi, T. Horikoshi, K. Hirayama, T. Tsuchikawa, Y. Kobayashi, Journal of Architecture, Planning and Environmental Engineering, 447, 17-26, (1993)

14. Y. Kurazumi, K. Saito, T. Horikoshi, Japanese Journal of Biometeorology 31(2), 75-84, (1994)

15. Y. Kurazumi, N. Matsubara, T. Tsuchikawa, E. Kondo, J. Ishii, K. Fukagawa, Y. Ando, Y. Yamato, K. Tobita, T., Horikoshi, Japanese Journal of Biometeorology, 48(4), 129-144 (2011)

16. K. Nishida, M. Mitsuyasu, S. Yoshida, S. Shirozawa, Irrigation, Drainage and Rural Engineering Journal, 305(85-2), I_253-I_263 (2017)

17. K. Fukagawa, Y. Kurazumi, Y. Yamato, K. Tobita, H. Hase, S. Han, H. Oishi, Z. Cao, The 7th International Cost Engineering Council World Congress \& The 14th Pacific Association of Quantity Surveyors Congress, Singapore, July 23-27 2010, 1-10 (2010)

18. Y. Kurazumi, K. Fukagawa, E. Kondo, T. Sakoi, Journal of Ergonomics, 4(2), 1-7 (2014)

19. Y. Kurazumi, E. Kondo, K. Fukagawa, R. Hashimoto, A. Nyilas, T. Sakoi, T. Tsuchikawa, Health, 9(4), 601-621 (2017)

20. Y. Kurazumi, R. Hashimoto, A. Nyilas, K. Yamashita, K. Fukagawa, E. Kondo, Y. Yamato, K. Tobita, T. Tsuchikawa, Health, 10(7), 928948 (2018) 